\title{
IS THE INTEGRATION OF THE STEM DISCIPLINES WITH COMPUTING OCCURRING AT THE SECONDARY SCHOOL LEVEL IN K-12 SCHOOL SYSTEM? AN EXPLORATORY STUDY
}

\author{
Sushma Mishra, Robert Morris University, mishra@rmu.edu \\ Donna Cellante, Robert Morris University, cellante@rmu.edu \\ Diane Igoche, Robert Morris University, igoche@rmu.edu
}

\begin{abstract}
Computing plays a pervasive role in today's academic, social, and economic life. Introducing young children to the computing field is important to keep them at an advantage in their future careers. Unfortunately, there is a lack of integration of computing with other STEM disciplines in the K-12 levels. The goal of this study is to understand the current practices in place in secondary schools to integrate computing with the STEM disciplines in the curriculum especially for middle and high school students. This study investigates strategies that can be adopted to strengthen the integration of STEM disciplines with computing.
\end{abstract}

Keywords: STEM+C, K-12, Computing, Education, Information Technology (IT)

\section{INTRODUCTION}

Training school students in computing skills is critical to young minds as it provides a fundamental framework of structured thought process, logical application, and problem solving attitude. Computational thinking encourages students to be able to think about problems in a holistic manner and see the overlap between computing and other disciplines, especially STEM. These commonalties or linkages that cross over disciplines are essential in developing well prepared consumers of computing skills that allow better utilization of problem solving in all facets of our lives. Computational thinking (CT) is viewed as the core of all STEM disciplines (Grover and Roy, 2013). A perspective that breaks down the meaning of CT for high school curricula is derived from computer science principles used by College Board and the National Science Foundation (NSF) (http://www.csprinciples.org/). These principles establish computing as primarily aimed towards problem solving; and it allows innovation in other disciplines such as sciences, social sciences, humanities, engineering, business and medicine (Grover and Roy, 2013). Lee et al. (2011) argue that computing shares fundamental elements with mathematics, engineering, and design science and draws from their frameworks and extends that thinking in unique ways. The integration of computing with Science, Technology, Engineering and Mathematics (STEM) disciplines in particular has deeper and far reaching implications for younger generations of adults in schools.

Even though there is broad acknowledgement that computing pervades all aspects of the global economy, there is a lack of integration of computing with other STEM disciplines in the secondary school curricula (Grover and Roy, 2013). Basic literacy in math and science is considered essential, but it is critical that the integration of computing with these fundamental skills be established early in K-12 students' minds. Students in possession of computational competencies will be better positioned to take advantage of a world with ubiquitous computing. Introducing computing emphasis in a school requires a transformation of educational practice and philosophy, which often results in making it a more supportive learning environment that fosters motivation and academic aspirations (Prettyman, S., Ward, C. Jauk, D. and Awad, G., 2012).

It is important to understand how secondary schools are dealing with the challenges of developing a work force that understands the core principles of computational thinking, is able to see and work on linkages between computing and STEM disciplines, and is able to contribute to economic and social growth through application of this innovative and integrated way of addressing problems. The goal of this study is to understand the current practices 
in place in secondary schools to integrate computing with the STEM disciplines in the curriculum especially for middle and high school students. This study also investigates strategies that can be adopted to strengthen the integration of STEM disciplines with computing. The specific research questions that this study poses are:

RQ1: What are you doing in your school district to integrate STEM + C into the curriculum?

RQ2: How can STEM + C integration be strengthened in middle and high schools?

The rest of this paper is organized in the following way. The introduction section is followed by a critical analysis of the extant research literature in the area of STEM $+\mathrm{C}$ integration in secondary school and strategies to strengthen this integration. The methodology section presents data collection and data analysis approaches used in this study and the results from the data. The results are followed by a discussions section presenting the implications of our findings for research and practitioners. It also outlines the contributions and limitation of this study. Finally, conclusions are drawn.

\section{LITERATURE REVIEW}

The fast changing digital infrastructure with adoption of embedded computers in every sphere of life has placed new demands on K-12 educators as well as students. It is imperative that young children in schools get an opportunity to learn technical skills and knowledge of computing, such as programming, logic, discrete mathematics, etc., in order to be a contributor to the digital economy of today and the future (Snapp and Neumann, 2015). The Bureau of Labor Statistics projects that by 2020, 62 percent of new jobs in the STEM occupations will require computer science knowledge (Bureau of Labor Statistics, 2012). Computer scientists across the nation agree K-12 learning should be combined with instruction in computational thinking that develops the logical foundation of computer science and includes abstract structures, algorithmic processes, Boolean logic, and discrete mathematics (Snapp and Neumann, 2015).

"STEM + Computing (STEM-C) Partnerships seek to advance a 21st century conceptualization of education in science, technology, engineering and mathematics (STEM) that includes computing. The "+ Computing" notation emphasizes that computing is integral to the practice of all the other STEM disciplines. Computing refers to the whole set of fundamental concepts and skills that will allow students to creatively apply and adapt computation across a range of application domains" (NSF, 2014). Fewer students are taking computing courses and are being prepared for computing careers than other career paths. The lack of computer science, especially the integration of computing with STEM disciplines, at secondary school level has repercussions in areas such as job market opportunities, national security and participation in global economy. It reduces the probability of students opting for a computer science major in college (Abdul-Alim, 2015). The need and importance of integrating computing into current and future curricula in the K-12 realm is critical (Babway et al, 2015).

Secondary school education has been providing fundamental literacy in math and science for a long time. In today's changing digital world with intensive information generating and processing requirements, it is crucial that the integration of computing with these fundamental skills be established early on at the K-12 level. Students in possession of computational competencies will be better positioned to take advantage of a world with ubiquitous computing (Grover and Roy, 2013). An early intervention in form of emphasis on problem solving at the secondary school level will alleviate problems with computer science courses and generate interest in students for viable career paths in this growing field with opportunities (Grover and Roy, 2013).

Mishra et al (2016) conducted a study to understand the status of STEM+C courses in South-Western Pennsylvania school districts. The results have shown an interest in creating a greater awareness of computing in the elementary, middle, and high school levels, especially at the middle school level. There is a need to introduce students to computing at an early age to expose them to the career options in the field and encourage an interest in computing applications and programs. The respondents noted that curriculum changes need to occur for computing courses to have a better focus at their respective schools. A respondent noted that courses tested in the state assessment tests will continue to receive greater attention over elective courses like computing due to the pressure on teachers to teach students to enable them successfully attempt the various assessments. 
Secondary schools offer traditional STEM and computing courses. But the state of integration of STEM with computing is underdeveloped. Computing as a tool to solve problems in any discipline including STEM is not emphasized. Even though there exists a curriculum that teaches the concepts of SETM and computing in a disparate manner, the integrational emphasis lacks. It is critical to assess the level of integration currently being offered in secondary school to understand the existent gaps in the curriculum. Secondary school students' perception of computing and its integration of other STEM disciplines could go a long way in shaping their career choices. It is important to understand how students are currently experiencing the STEM $+\mathrm{C}$ environment in secondary school to construct and implement meaningful technology programs that lead to the types of educational changes necessary for learning in the 21 st century.

A survey of secondary school teachers to understand the barriers and issues necessary to build a STEM $+\mathrm{C}$ curriculum in these schools suggests lack of resources at school districts and lack of commitment on part of school board members to embrace this "futuristic" approach to computing. Teachers lack training in latest technological tools, lack instructional material that guides them to learn and understand the integration issues better, and lack the confidence to pursue this education on their own time and at their leisure (Mishra et al, 2016). Computing emphasis in the secondary school curriculum requires a fundamental shift in educational practice and philosophy, which would result in fostering a supportive learning environment that motivates young minds and creates academic aspirations (Prettyman et al, 2012). Computing plays a pervasive role in today's academic, social, and economic life. It is important to assess the preparation and skills that secondary schools are offering to young minds of today in order to fulfill the demands of the current realities of global economy.

\section{METHODOLOGY}

A survey instrument of 21 questions was developed and distributed to 628 teachers (Business, Math, Technology Education and Computing), and Administrators in 76 schools in South-Western Pennsylvania via QuestionPro.com. The email addresses of the project sample was released to potential participants in the first week of March, and it was made available for participation for a period of three weeks. A reminder email was sent out to the previously emailed sample at the end of the third week to encourage more participation.

The survey instrument consisted of nine (9) open-ended questions. The researchers believed that it was important to gather the individual perspectives of the respondents on the integration of STEM $+\mathrm{C}$ in their schools and their thoughts on the appropriate level for this integration to begin.

\section{Demographics of Respondents}

There were a total of 26 responses, with 137 potential respondents viewing the survey, 68 embarking on the survey and $38 \%$ completing the survey. The responses were manually analyzed by the researchers; questions were analyzed based on question type (open ended or otherwise).

Twenty-eight percent (28\%) were elementary school teachers, $16 \%$ were teachers in the area middle schools, and $14 \%$ identified as high school teachers as shown in Figure 1 below. There were no responses from Administrators. Thirty-two percent (32\%) of the respondents have obtained a Bachelor's Degree, $68 \%$ have a Master's Degree and none of the respondents have received a Doctoral degree as shown in Figure 2 below. Sixty-eight percent $(68 \%)$ of the respondents identified as female and $32 \%$ identified as male. The respondents identified a diverse age range, $8 \%$ were between $21-30$ years of age, $20 \%$ were between $31-40$ years of age, $44 \%$ were in the $41-50$ range, and $28 \%$ were between 51-60 years old. 


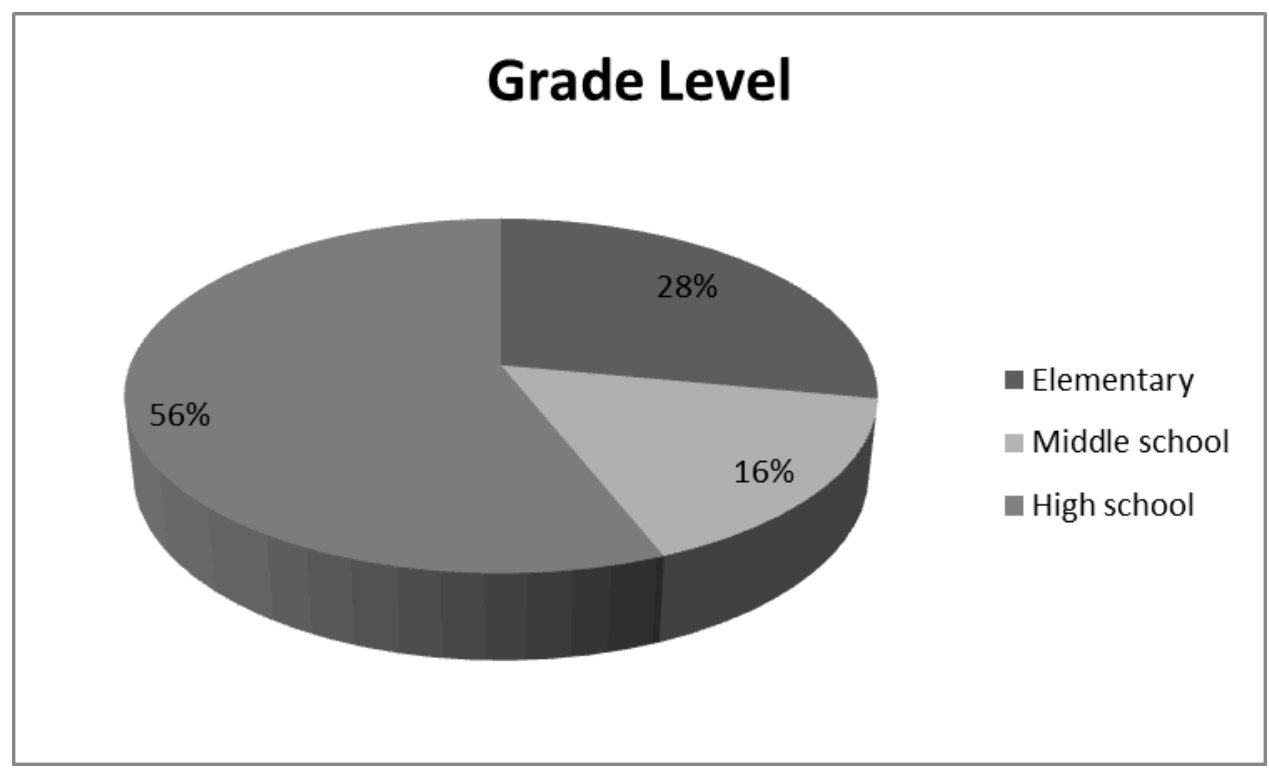

Figure 1. Respondents Level of Teaching

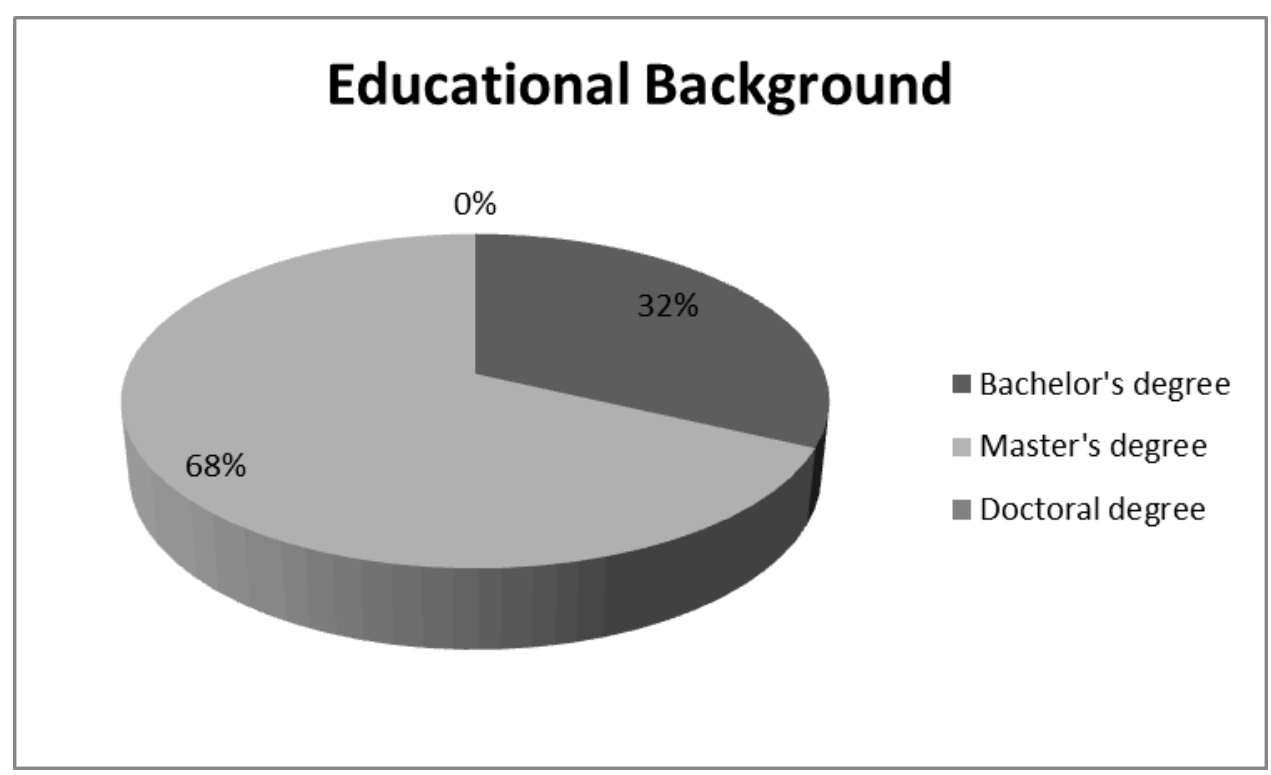

Figure 2. Educational Background of Respondents

\section{DISCUSSION}

The researchers used two major research questions which used several sub-questions to determine the integration of STEM + Computing $(\mathrm{STEM}+\mathrm{C})$ in public schools in South-Western Pennsylvania. The findings are discussed below.

In response to the survey question asking about what is currently being done, the overall response was very little. Many of the respondents stated that they did not know STEM $+\mathrm{C}$ was an option. Several respondents did mention that their school districts were looking to add more programs to middle and elementary school next year. STEAM (Science, Technology, Engineering, Arts, and Math) classes are part of the primary and middle school's curriculum, 
but not much integration. Some of the respondents indicated that the district offers STEM classes through other organizations.

In response to the question asking at what level is the integration of STEM+C in the curriculum starting in your school district, the respondents indicated that integration is beginning in the elementary school (about $40 \%$ ). Some integration (about $31 \%$ ) is also happening in the middle school.

The question asking about whether they have a special STEM $+\mathrm{C}$ program used in their district, the majority of the respondents indicated "no" (58\%). Of those that answered "yes", it happened mostly in the elementary school with programs such as STEM workshops, STEAM workshops, and Code.org (Grades 1-4). Of those that answered "no", the respondents did believe, however, that integration needs to begin in the elementary school $(52.6 \%)$ and/or in the middle school (42.1\%).

We next asked the respondents if they were getting any training for integrating STEM $+\mathrm{C}$. The majority responded that they had no training at all. We asked the respondents to indicate if it was important for them to get training in order to introduce these curricular changes. They explained that you can't teach without training; they need training to keep current in new curricular developments; and that the district needs to develop a district-wide scope and sequence. They indicated that an introduction to STEM $+\mathrm{C}$ would be helpful. They also responded that many "trainings" are simply selling a product.

Of those that responded "yes" that they were getting training, the kinds of training included STEM workshops with ACT48 hours attached, trainings with the children's museum, university trainings, and In-Service Day training. They indicated that were trained to use instructional materials $(28 \%)$, tools $(21 \%)$; videos $(19 \%)$, and tutorials $(19 \%)$. They reported that they received some form of training about two times per year only.

When asked how STEM $+\mathrm{C}$ integration could be strengthened in middle and high school, some of the respondents were very honest and said, "I don't know." Of those that did respond, they mentioned some ways for this to happen. They are as follows: offer education to all students through core classes for initial exposure and ways to integrate across all disciplines; emphasis on keyboarding, programming, and robotics; make it more fluent with the curriculum so it fits naturally; and actually training educators in the integration of STEM + Computing (develop a system-wide approach to STEM).

The survey question that asked if you worked with curricular units regarding integrating computing, the responses were mixed. Integrating computing with math (15\%); integrating computing with engineering (13\%); integrating computing with science (13\%); integrating computing with technology $(32 \%)$; integrating computing with all disciplines (11\%); and integrating computing with no disciplines (4\%) indicates that there is not much consistency with integrating STEM $+\mathrm{C}$ into the curriculum.

The results of the survey indicate that STEM $+\mathrm{C}$ needs to be clearly defined before it can be integrated into the curriculum. Also, teachers cannot do it themselves. Sure, teachers can introduce students to robotics and coding, but it needs to be introduced in a more structured environment. The administration needs to develop a district-wide scope and sequence plan for integration.

Training educators is key to integration taking place. An introduction to STEM $+\mathrm{C}$ through an in-service workshop could be an effective way to excite the whole district. Perhaps a train-the-trainer model could work. In this model, inexperienced teachers receive coaching and mentoring from experienced teachers or facilitators. Several teachers from each level (elementary, middle, and high school) could be formally trained in STEM + C. Those teachers would return to their school buildings and train other teachers until all teachers in each discipline and grade level had been trained. Professional development opportunities for teachers are important for teachers to get educated in new means of teaching fundamental STEM $+\mathrm{C}$ concepts to students in an engaging manner.

Research in the area of professional development for teachers suggests that it is critical to have frequent training opportunities for teachers to be able to get interested in latest technologies and in return encourage students to do 
the same. A study into teachers' preparedness to teach science and engineering standards using models showed that teachers are unprepared to use modeling concepts in their lessons, and middle school teachers required around 64 hours of training to reach a comfort level with the problem solving using models (Haag and Colleen, 2015). Another project looked closer at the teachers responsible for teaching Advanced Placement Computer Science and attempted to increase student interest by improving the teachers. In the state of California, it was found that no teaching certification for computer science existed (it was considered a subset of business), and technical $83 \%$ of teachers were teaching computing outside their certified subject area. An intervention was conducted with a cohort of grade school computer science teachers to give them training, support, curriculum, and a broader understanding of computing careers. Improving the teachers of the advanced placement course showed the enrollment rise nearly threefold over a three-year period after the intervention, and female participation quadrupled (Goode, 2007). Better trained teachers will entice more students into computing courses, and this increase will undoubtedly include female participants.

\section{CONCLUSION}

This study investigated the status of integration of STEM + Computing in school districts in South-Western Pennsylvania. The purpose was to determine how the integration of the STEM + Computing is being implemented into the public school curricula. Public education is just beginning to delve into STEM; little has been done with STEM + Computing. This study emphasizes the significance of integrating STEM disciplines with computing education in a holistic manner. This integration would lay the foundation for computational thinking in K-12 students and prepare them for problem solving and solution oriented opportunities in the future.

\section{REFERENCES}

Abdul-Alim, J. (2015). Students not prepared for careers in computer science. Diverse Issues in Higher Education.

Babaway, Schmitt, et al. (2013). Expectations of computing and other STEM students: A comparison for different class levels, IEEE Frontiers in Education Conference, 7, p. 1657-1663. DOI: 10.1109/FIE.2013.6685120.

Bureau of Labor Statistics report (2012) Retrieved on April 8, 2016, http://www.bls.gov/opub/mlr/2012/01/art5full.pdf

Goode, Joanna. If you build teachers, will students come? The role of teachers in broadening computer science learning for urban youth. Journal of Educational Computing Research 36, No. 1 (2007): 6588.

Grover, S. and Roy, P. (2013). Computational thinking in K-12: A review of the state of the field. Educational Researcher, 42(1), 38-43, DOI: 10.3102/0013189X12463051.

Haag, Susan, and Colleen Megowan. (2015). Next generation science standards: A national mixed-methods study on teacher readiness. School Science and Mathematics, 115(8), 416-426.

Lee, I., Martin, F., Denner, J., Coulter, B., Allan, W., Erickson, J., Werner, L. (2011). Computational thinking for youth in practice. ACM Inroads, 2, 32-37.

Mishra, S., Cellante, D., Igoche, D. and Kavanaugh, L. (2016). The status of computing courses under STEM $+\mathrm{C}$ in K-12 schools in Southwestern PA. In Proceedings of North Eastern Decision Sciences Institute (NEDSI) Conference, March 31-April 2, Alexandria, VA. 
National Science Foundation, STEM-C partnerships: Computing education for the $21^{\text {st }}$ century (STEM-CP: CE21). Washington, DC: Program Solicitation, NSF14-523, 2014.

Prettyman, S., Ward, C., Jauk, D. and Awad, G. (2012). 21st century learners: Voices of students in a one-toone STEM environment. Journal of Applied Learning Technology, 4(2).

Snapp, R. R., \& Neumann, M. D. (2015). An amazing algorithm. Mathematics Teaching in the Middle School, 20(9), 540-547. 